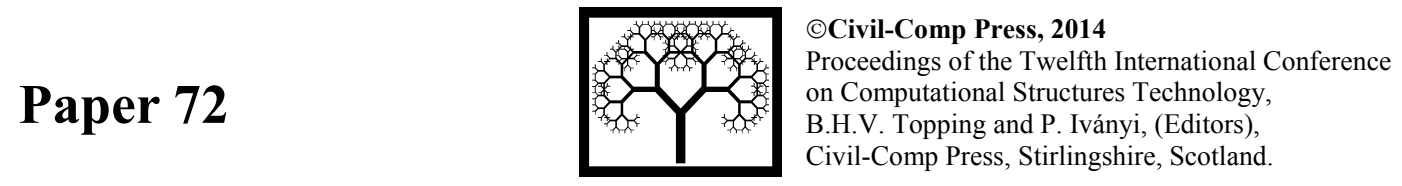

\title{
Modifications in the Dynamic Properties of a Structure due to Human Actions
}

\author{
J. Fernández, L. Hermanns, A. Fraile and E. Alarcón \\ Department of Structural Mechanics and Industrial Constructions \\ University of Technology Madrid, Spain
}

\begin{abstract}
The interest for modelling of human actions acting on structures has been recurrent since the first accidents on suspension bridges in the nineteenth century such as Broughton (1831) in the U.K. or Angers (1850) in France. Stadiums, gymnasiums are other types of structure where human induced vibration is very important. In these structures a particular phenomenon appears such as the interaction personstructure (lock-in), the person-person synchronization, and the influence of the mass and damping of the people in the structural behaviour. This paper focuses on the latter topic.

In order to evaluate these property modifications several tests have been carried out on a stand-alone building. For the test an electro-dynamic shaker was installed at a fixed point of the gym slab and different groups of people were located around the shaker.

The dynamic characteristics of the structure without people inside have been calculated by two methods: using a three-dimensional finite element model of the building and by operational modal analysis. These calculated experimental and numerical values are the reference values used to evaluate the modifications in the dynamic properties of the structure.
\end{abstract}

Keywords: human induced vibration, damping ratio, operational modal analysis, structure dynamic properties.

\section{Introduction}

Problems with excessive vibration that have occurred on some high profile structures in recent years while they were exposed to human-induced dynamic loading (the Millennium Bridge in London, Solférino passerelle in Paris, the Millennium Stadium in Cardiff) triggered a lot of research into modelling the 
human-induced loads (such as walking, jumping, swaying, etc.) and estimation of the responses they generate. Some advances in this area have already been made [1, 2]. However, what is still under researched and not well understood is the personstructure interaction. This interaction occurs because humans are quite sensitive vibration receivers and highly complex dynamic systems. As such, they tend to change their behaviour when they perceive strong structural vibrations in both lateral and vertical directions [3].

One approach to person-structure interaction looks into the influence of people's presence on the structure on dynamic properties of the human-structure system, and consequently on the structural response. This paper focuses on the study and analysis of the influence of people standing or sitting on the dynamic behaviour of a structure.

The first part of the paper describes the structure investigated and the dynamic test performed. After this, the operational modal analysis is briefly described and then, the results of the dynamic test and the work conclusions are presented.

\section{Test structure}

The test we shall present was performed on a stand-alone building, designed to be a gymnasium, which belongs to the School of Industrial Engineering of the Technical University of Madrid. The structure was finished in the 1950's and, unfortunately, the original as-built drawings are not available.

The photograph displayed in Figure 1 shows general views of the structure, which is neither regular nor symmetric. Many structural details are responsible for that. For example, a large window or an access stair that seems to constrain horizontal displacements at the second bay.

Interior walls are set to split the building in two parts. The big windows on the left belong to the gym, while the small windows on the right, just above the access stairs, belong to the dressing rooms, toilets and other small rooms distributed in two floors. Tests and measurements where only performed on the left hand side.

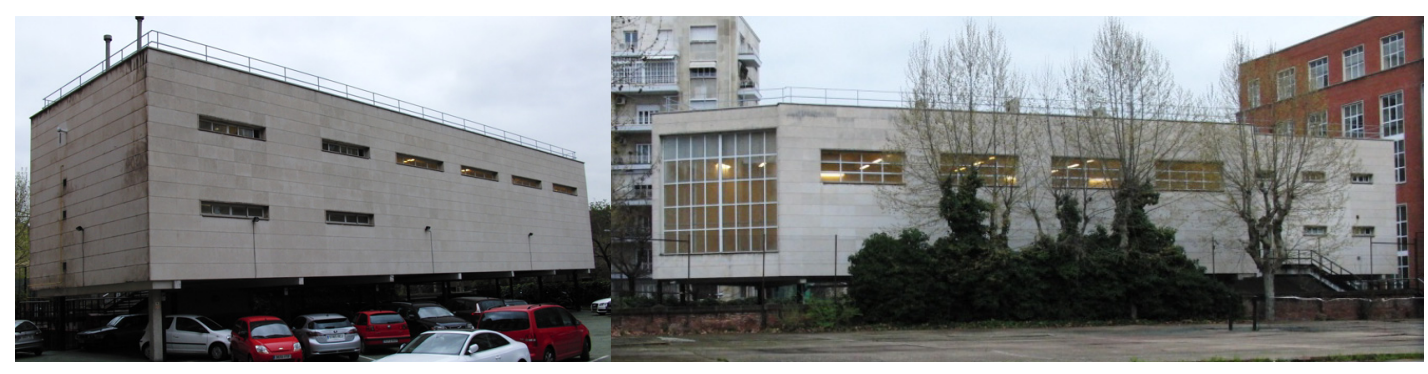

Figure 1: External photographs of the structure. 


\section{Test layout and measurements equipment}

Several dynamic tests were performed on the gym slab. In all of them, an electrodynamic shaker was placed at fixed location while accelerations and displacements were recorded at selected points of the structure. The test layout is shown in Figure 2
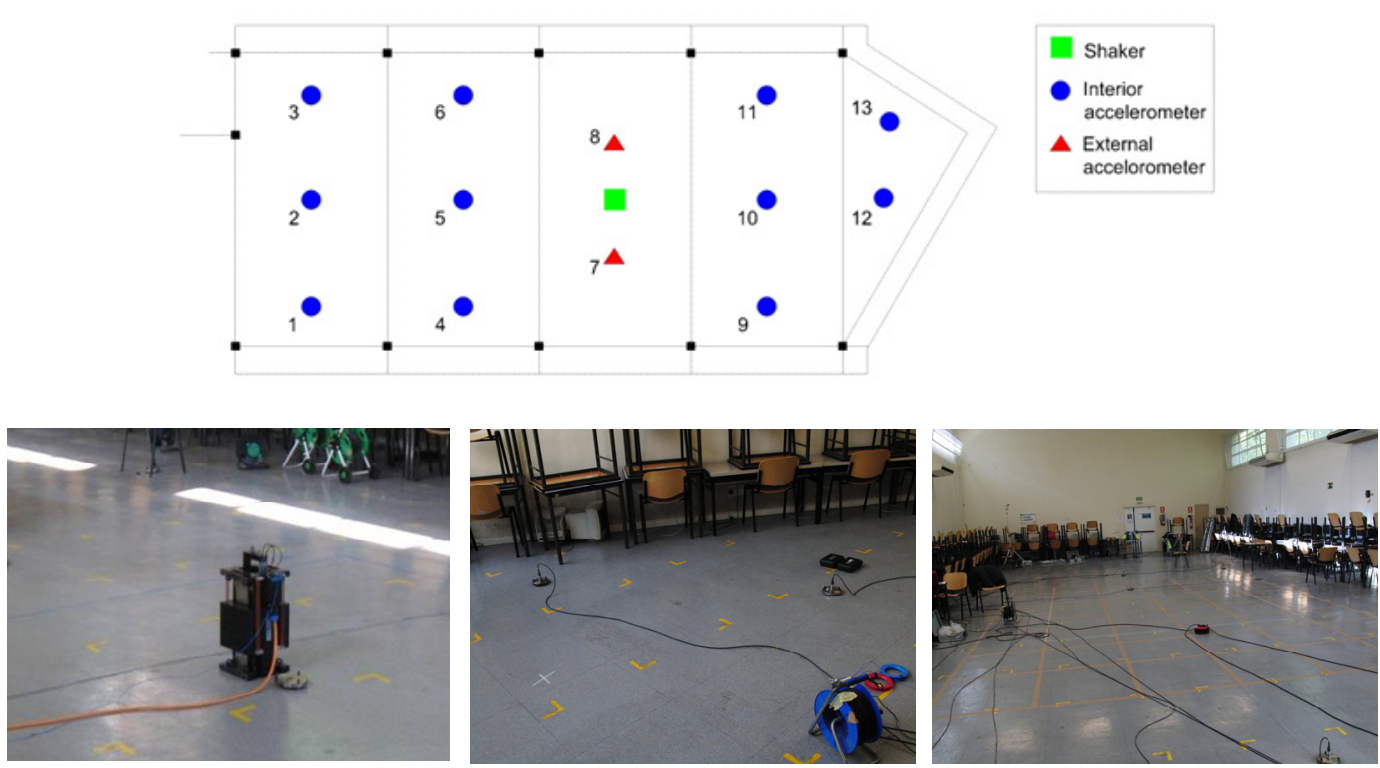

Figure 2: Shaker and accelerometer test layout and three photographs of the instrumentation

The electro-dynamic shaker APS $113 \mathrm{HF}$ is used together with an amplifier APS 145 and a signal generator Hameg HM 8150 that provides the suitable commands. The latter are harmonic signals displaying variable frequencies (chirp), in the range of interest (between 1 and $40 \mathrm{~Hz}$ ), $100 \mathrm{~s}$ long. In Figure 3 an acceleration time history and the acceleration PSD of three chirps are shown. A PCB 288D01 sensor was placed at the shaking mass, while 13 other accelerometers (six Endevco 77541000 and seven PCB 393A03, see Figure 2) where distributed along the slab measuring along the vertical direction.
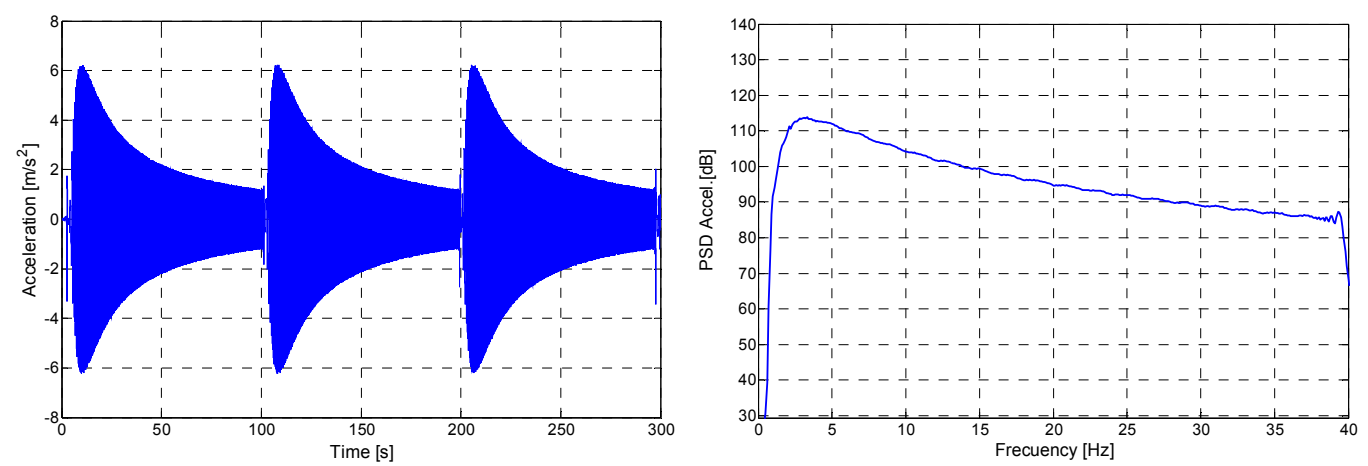

Figure 3: Chirp signal. 
Different groups of people were distributed around the shaker point in a limited area centered in the second bay at measured locations. The groups were varying in number of people $(12,24$ and 48$)$ and their posture (sitting and standing) in order to study the influence in the dynamic properties of the structure. All participants were weighted before starting the tests in order to assess the total load in each moment.

Figure 4 illustrates the group distribution schemes around the shaker location and some photographs of the tests. The shaker has been remarked with red circles in the photographs.
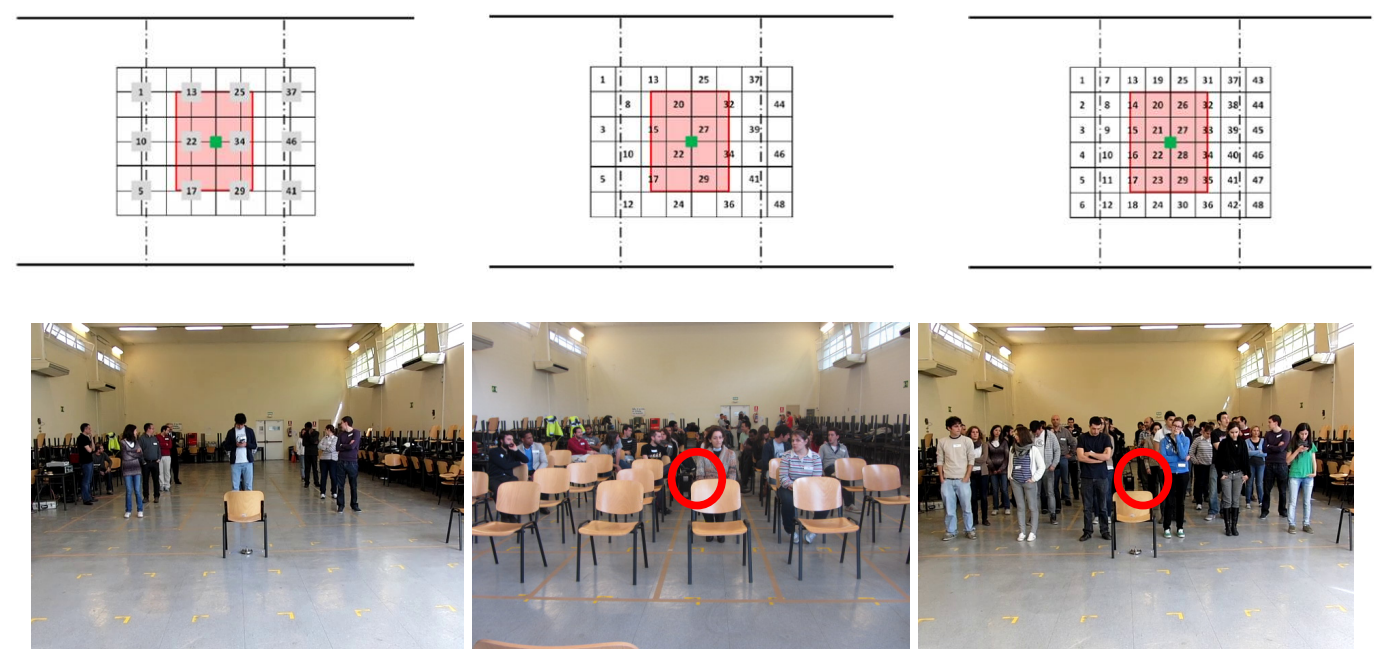

Figure 4: People distribution and three photographs taken while performing the tests

\section{Results}

\subsection{Modal parameter estimation}

In the field of civil and structure engineering, system identification is applied mainly for modal analysis and Structural Health Monitoring. Modal analysis is based on the determination of modal parameters of a structural system which represent an optimal model, or basis, and can be used to describe the dynamics of a structural system. These modal parameters are modal frequencies, modal damping and modal vectors [4].

In the case of parametric system identification methods, the dynamic behaviour of a system is described using mathematical models, and there are mathematical relationships between the modal parameters and the estimated model parameters. It is therefore common to use experimental modal analysis as a synonym for system identification. This section presents the identification of modal parameters in state space models.

The typical time-domain stochastic system identification methods work on a discrete time state-space modal 


$$
\begin{aligned}
& x_{t+1}=A x_{t}+B u_{t} \\
& y_{t}=C x_{t}+D u_{t}
\end{aligned}
$$

where

- $\mathrm{t}$ denotes the sampling instant with constant sampling time $\Delta t$;

- $\mathrm{y}_{\mathrm{t}} \in R^{n_{0}}$ is the measured output vector;

- $\mathrm{u}_{\mathrm{t}} \in R^{n_{i}}$ is the measured input vector;

- $\mathrm{x}_{\mathrm{t}} \in R^{n_{s}}$ is the state vector;

- $\mathrm{A} \in R^{n_{s} x n_{s}}$ is the transition state matrix describing the dynamics of the system;

- $\mathrm{B} \in R^{n_{s} x n_{i}}$ is the input matrix;

- $\mathrm{C} \in R^{n_{0} \times n_{s}}$ is the output matrix, which is describing how the internal state is transferred to the output measurements $y_{t}$;

- $\mathrm{D} \in R^{n_{0} x n_{i}}$ is the direct transmission matrix;

- The noise vectors comprise immeasurable vector signals assumed to be zero-mean, white vector sequences with covariance matrices

$$
w_{t} \rightarrow N(0, Q) \quad v_{t} \rightarrow N(0, R)
$$

Equation (1a) is known as the state equation and equation (1b) is known as the observation equation. In the case of output-only vibration testing, only the response of a structure is measured, while the input sequence $u_{t}$ remains unmeasured. Thus, Equation (1) results in a purely stochastic system:

$$
\begin{aligned}
& x_{t+1}=A x_{t}+w_{t} \\
& y_{t}=C x_{t}+v_{t}
\end{aligned}
$$

From the eigenvalues of matrix $\mathrm{A}$ it is possible to get the natural frequencies and the modal damping ratios. The eigenvectors can be obtained from matrix $\mathrm{C}$.

\subsection{Previous results}

Looking for another aim of this project, additional tests were carried out in the empty gymnasium building. Dynamic properties of the structure were identified using Operational Analysis Modal described previously. Furthermore, a finite element (FE) model of the whole building had been set up using ANSYS. Figure 5 displays a general view of the model geometry. 


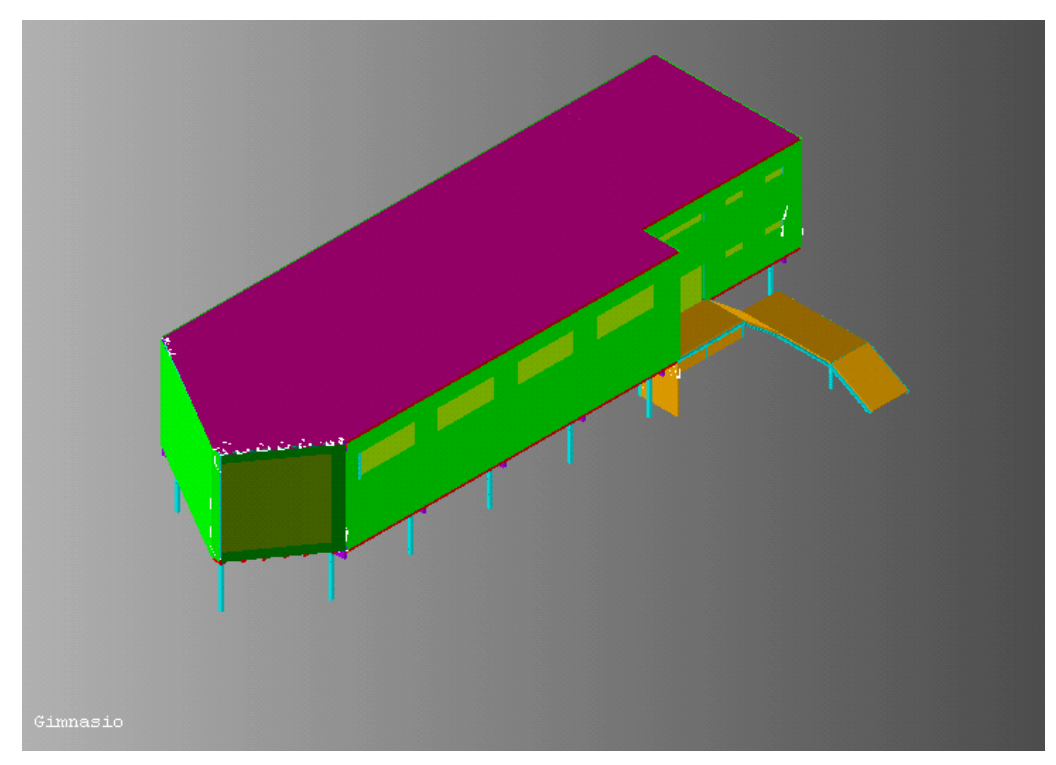

Figure 5: Finite element model

The model has been tuned based on test results: vibration frequencies and frequency response functions among the shaker sensor and those on the slab. Flexural vibration modes associated with vertical motions of both slabs are presented in Table 1 for both the model and the identification through SSI. Relative errors are below $4 \%$ in all cases.

\begin{tabular}{|c|c|c|c|}
\hline Mode & $\begin{array}{c}\text { Experimental } \\
\text { Freq. }(\mathrm{Hz})\end{array}$ & $\begin{array}{c}\text { Numerical } \\
\text { Freq. }(\mathrm{Hz})\end{array}$ & Error (\%) \\
\hline $1^{\text {st }}$ Floor Bending & 5.74 & 5.71 & 0.6 \\
\hline $2^{\text {sd }}$ Floor Bending & 6.75 & 6.59 & 2.3 \\
\hline $3^{\text {rd }}$ Floor Bending & 8.52 & 8.20 & 3.8 \\
\hline $4^{\text {th }}$ Floor Bending & 10.85 & 10.89 & 0.4 \\
\hline
\end{tabular}

Table 1: Flexural eigen frequencies comparison

\subsection{New test results}

Commercial software ARTEMIS Modal Pro [5] has been used to perform the Operational Modal Analysis with the data of the new tests described in point III, with the structure occupied by people. 
A post-processing of the original data is required. The post-processing consists of a high-pass filter at a frequency of $0.5 \mathrm{~Hz}$ and a decimation of order 32, from the sampling frequency of $4096 \mathrm{~Hz}$ to $128 \mathrm{~Hz}$ in order to facility the vibration modes detection. For instance, the acceleration measured by one of the accelerometers is shown in figure 6 . In some frequencies the value of the signal increases. And the structure natural frequencies are identified in the power spectral density figure, on the right.
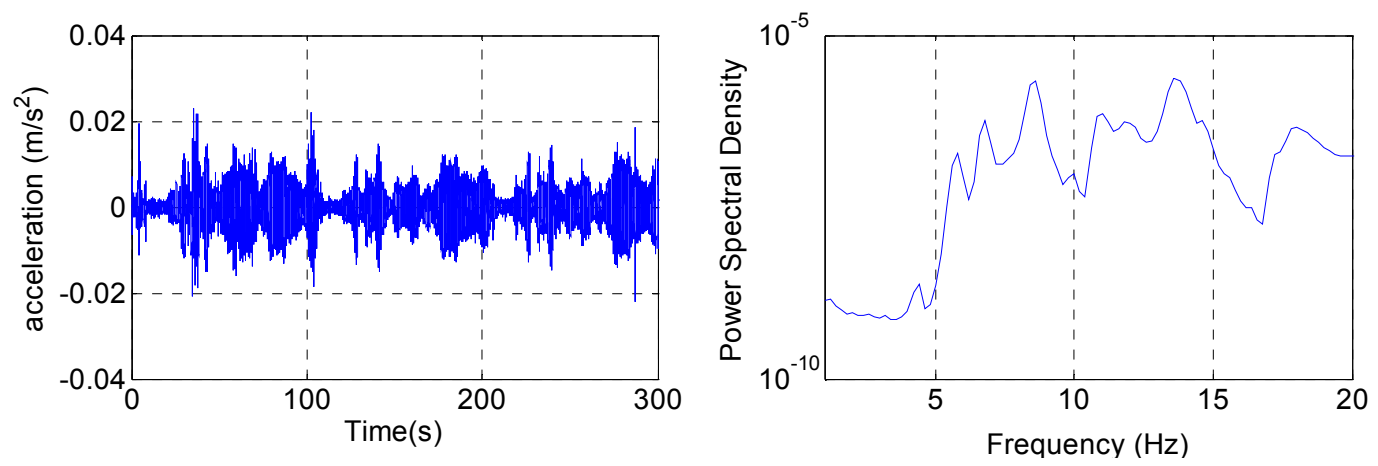

Figure 6: Measured signal by one accelerometer during the chirp excitation

The acceleration time histories have been processed using the Stochastic Subspace Identification Method (SSI) and the Enhanced Frequency Domain Decomposition (EFDD) to estimate vibration mode shapes and damping values [6].

In Stochastic Subspace Identification techniques a parametric model is fitted directly to the time series data measured by the accelerometers. The parameters of the model can be adjusted to change the way the model fits to the data. In general one looks for the set of parameters that minimizes the deviation between the predicted system response (predicted response) of the model and measured system response (measured response) [6].

The Frequency Domain Decomposition method (FDD) is a technique where each mode is estimated as a decomposition of the system's response spectral densities into several single-degrees-of-freedom systems.

The Enhanced Frequency Domain Decomposition emerges as an improvement of the FDD method offering the possibility of estimating the damping ratio. The estimation of the eigenfrequencies and mode shapes is also improved

In this case, in addition to the natural frequencies, the damping ratio has been calculated in order to study the modifications in the structure behaviour due to the presence of groups of people on the floor. The results of the operational modal analysis of the measured data are illustrated in Figure 7 and Table 2. In the figure the four vertical mode shapes for the configuration with 48 standing people are presented. These correspond modes are the typical bending modes of a floor. The different colours indicate the vertical displacement of the floor and the sensor location is marked with arrows. 

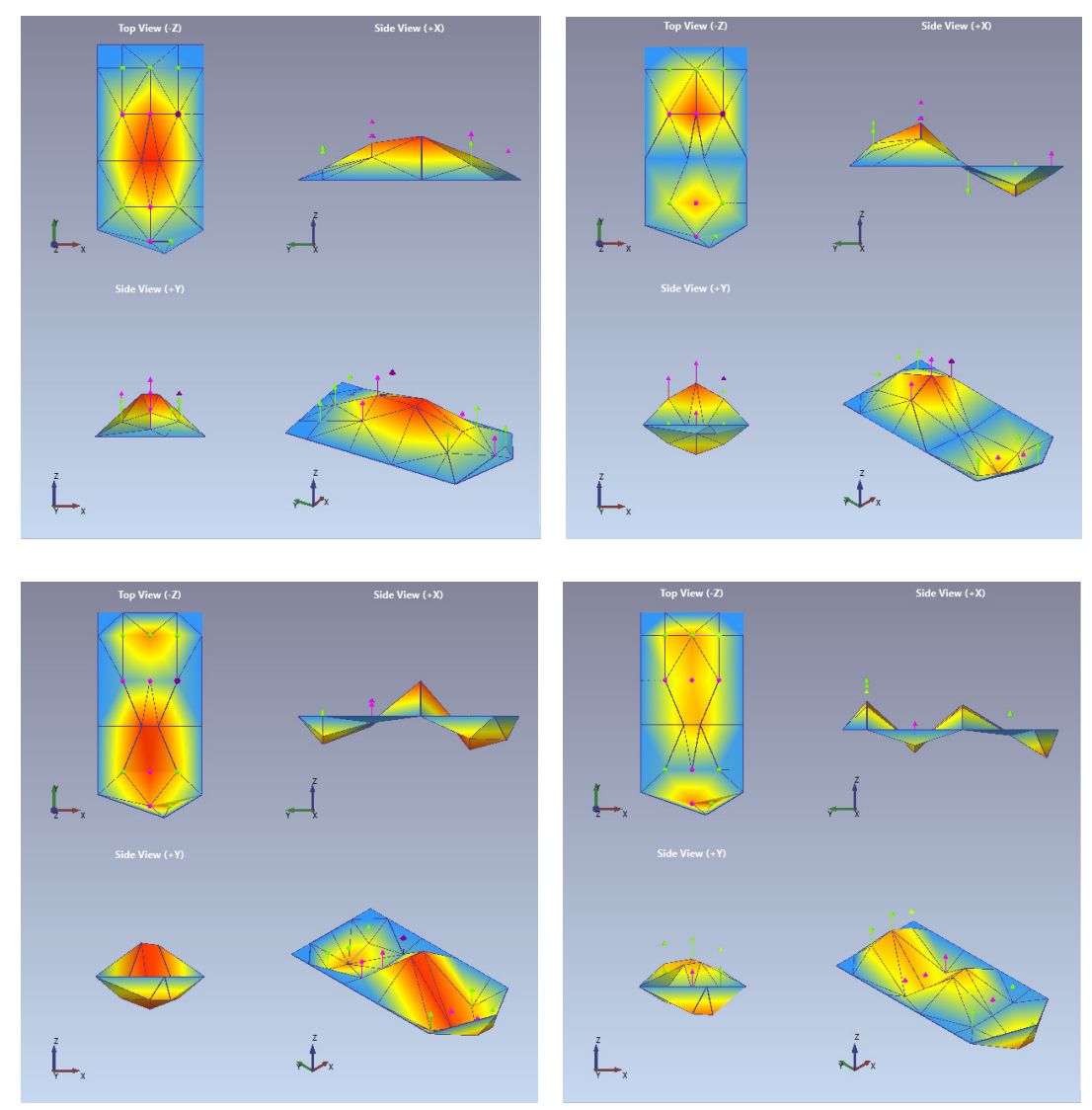

Figure 7: Vertical mode shapes

\begin{tabular}{|c|c|c|c|c|c|c|c|c|c|c|}
\hline \multirow[b]{2}{*}{ Test } & \multirow[b]{2}{*}{$\begin{array}{l}N^{o} \\
p a x\end{array}$} & \multirow[b]{2}{*}{ Posture } & \multicolumn{2}{|c|}{$1^{\text {st }}$ Floor Bending } & \multicolumn{2}{|c|}{$2^{\text {sd }}$ Floor Bending } & \multicolumn{2}{|c|}{$3^{\text {rd }}$ Floor Bending } & \multicolumn{2}{|c|}{$4^{\text {th }}$ Floor Bending } \\
\hline & & & $\begin{array}{c}\text { Frequenc } \\
y(\mathrm{~Hz})\end{array}$ & $\begin{array}{c}\text { Damping } \\
(\%)\end{array}$ & $\begin{array}{c}\text { Frequenc } \\
y\left(\mathrm{~Hz}^{2}\right)\end{array}$ & $\begin{array}{c}\text { Dampin } \\
\text { g(\%) }\end{array}$ & $\begin{array}{c}\text { Frequenc } \\
y(\mathrm{~Hz})\end{array}$ & $\begin{array}{c}\text { Damping } \\
\text { (\%) }\end{array}$ & $\begin{array}{c}\text { Frequenc } \\
y(\mathrm{~Hz})\end{array}$ & $\begin{array}{c}\text { Damping } \\
(\%)\end{array}$ \\
\hline 1 & 48 & Sitting & 5.72 & 6.370 & 6.94 & 2.043 & 8.74 & 3.340 & 11.12 & 2.744 \\
\hline 2 & 24 & Sitting & 5.82 & 4.313 & 6.99 & 1.534 & - & - & 11.06 & 2.031 \\
\hline 3 & 12 & Sitting & 5.81 & 3.268 & 6.957 & 1.343 & 8.78 & 2.80 & 11.03 & 2.040 \\
\hline 4 & 48 & $\begin{array}{c}\text { Standin } \\
\mathrm{g}\end{array}$ & 5.84 & 5.406 & 6.89 & 1.552 & 8.75 & 3.621 & 11.15 & 2.846 \\
\hline 5 & 24 & $\begin{array}{c}\text { Standin } \\
\text { g }\end{array}$ & 5.78 & 4.042 & 6.95 & 1.3979 & 8.79 & 2.920 & 11.03 & 2.164 \\
\hline 6 & 12 & $\begin{array}{c}\text { Standin } \\
\mathrm{g}\end{array}$ & 5.80 & 3.729 & - & - & 8.78 & 2.890 & - & - \\
\hline
\end{tabular}

Table 2: Operational modal analysis results. Frequencies and damping ratio

The results of frequency and damping obtained by the modal analysis are presented in Table 2 . The frequency values hardly change but it can be seen that the damping ratio usually increase with increasing the number of people in all modes. For example, in the case of people sitting, the damping ratio of the first mode changes from $3.268 \%$ with 12 people (test 3 ) to $6.370 \%$ with 48 people (test 1 ). Furthermore, in the first and second mode the damping ratio is higher in the tests with people sitting than standing people tests: for the test 1 (48 sitting people) the 
damping value is $6.370 \%$ and it goes down to 5.406 for test 4 (48 standing people). Figure 8 shows a resume graphics of these results.

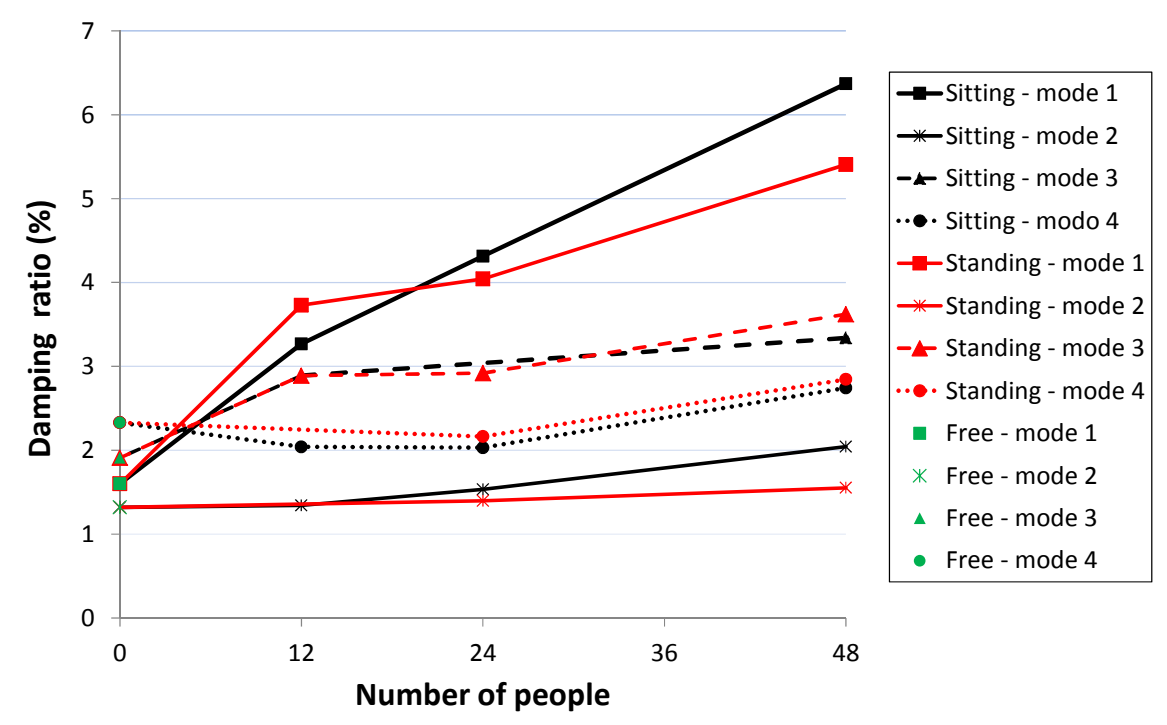

Figure 8: Damping ratio of the structure as a function of the number of people (sitting and standing)

If we compare the new damping values with the values of the empty building tests (in colour green in Figure 8) it can be seen that there is an increase in all cases except in mode 4. Figure 9 displays the damping increment regarding the damping of the empty structure.

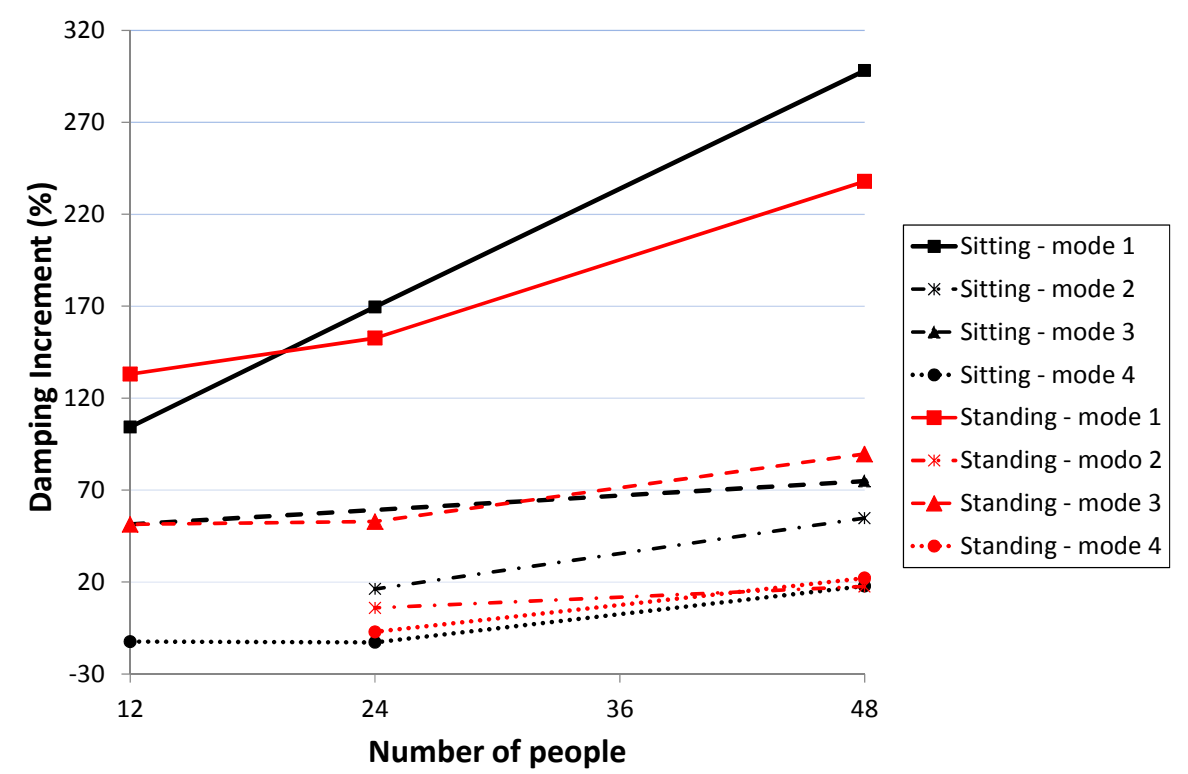

Figure 9: Damping ratio increment as a function of the number of people (sitting and standing) 


\section{Conclusions}

The main goal of this paper is to study the influence of crowds in the dynamic characteristics of a structure. To this end a series of tests have been conducted on a real structure designed to be a gymnasium, which has natural frequencies within the range of the excitation. Groups of people, sitting and standing, have been participated during in order to analyze the human-structure interaction.

Dynamic properties identification have been carried out and a finite element model of the structure have been performed to simulate the test results. The model can be used in the future to obtain the structure response with other excitations, varying the number of people, their location and their posture. A future work is the introduction of individual models of each person, like the model proposed by Griffin with different masses and damping ratios $[7,8]$.

Test results determine that the presence of group of people on the structure increased the damping ratio of the new human-structure system compared with the damping of the empty structure. Furthermore, according to the results it can be seen that the damping ratio is higher in the tests with people sitting than standing people. The frequency values hardly change in all cases.

\section{Acknowledgment}

Authors would like to thank the Spanish Ministry of Science and Innovation for sponsoring this work through Research Project BIA2011-28493.

\section{References}

[1] Ellis B.R. and Ji T., Loads generated by jumping crowds; numerical modeling, The structural Engineer 82 (17), 35-40, 2004

[2] Sim J.H.H., Human-structure interaction in cantilever grandstands, Ph.D. Thesis. University of Oxford, 2006.

[3] S. Zivanovic, I.M. Diaz and A. Pavic., Influence of Walking and Standing Crowds on Structural Dynamic Properties. IMAC-XXVII 2009

[4] F.J.Cara, J.Carpio, J.Juan and E.Alarcón. Computational Methods for Identification of Vibrating Structures. 12th International Conference on Civil, Structural and Environmental Engineering Computing, 2009

[5] Artemis Modal Pro v2.5. Structural Vibration Solutions A/S. Denmark. 2014

[6] Brinker R., Ventura C., Andersen P., Damping Estimation by Frequency Domain Decomposition, IMAC XIX, 2001.

[7] Y. Matsumoto and M.J. Griffin. Mathematical models for the apparent masses of standing subjects exposed to vertical whole-body vibration. Journal of Sound Vibration. 2002

[8] L.Wei and M.J. Griffin. Mathematical models for the apparent masses of the seated human body exposed to vertical vibration. Journal of Sound Vibration. 1997 